\title{
Mutual bootstrapping between language and analogical processing
}

\author{
DEDRE GENTNER AND STELLA CHRISTIE*
}

Northwestern University

Abstract

What makes us so smart as a species, and what makes children such rapid learners? We argue that the answer to both questions lies in a mutual bootstrapping system comprised of (1) our exceptional capacity for relational cognition and (2) symbolic systems that augment this capacity. The ability to carry out structure-mapping processes of alignment and inference is inherent in human cognition. It is arguably the key inherent difference between humans and other great apes. But an equally important difference is that humans possess a symbolic language.

The acquisition of language influences cognitive development in many ways. We focus here on the role of language in a mutually facilitating partnership with relational representation and reasoning. We suggest a positive feedback relation in which structural alignment processes support the acquisition of language, and in turn, language-especially relational language-supports structural alignment and reasoning.

We review three kinds of evidence (a) evidence that analogical processes support children's learning in a variety of domains; (b) more specifically, evidence that analogical processing fosters the acquisition of language, especially relational language; and (c) in the other direction, evidence that acquiring language fosters children's ability to process analogies, focusing on spatial language and spatial analogies. We conclude with an analysis of the acquisition of cardinality - which we offer as a canonical case of how the combination of language and analogical processing fosters cognitive development.

* Correspondence address: Dedre Gentner, Department of Psychology, Northwestern University, 2029 Sheridan Road, Swift Hall 213, Evanston, IL 60660, USA. E-mail: gentner@ northwestern.edu. This research was supported by NSF grant SBE-0541957, the Spatial Intelligence and Learning Center (SILC). 
Keywords

language and cognition, analogy, relational language, analogical processing.

\section{Introduction}

Humans are prodigious learners. More than any other feature, our ability to learn and adapt to different circumstances within the same genome distinguishes us from other species. Some of our cognitive prowess stems from abilities shared with other species, such as associative learning. But in many aspects of intelligence — such as the ability to learn and use abstractions, and to generalize them from particulars - we seem to be paragons. In particular, we excel at the ability to engage in relational matching and reasoning, even compared to other intelligent species (Gentner 2003; Penn et al. 2008; Premack 1983). Our language abilities are equally outstanding. For example, we are able to learn arbitrary symbols, including symbols for abstractions and recursive symbols such as the set of all sets. Crucially, we are able to invent and learn terms for relations as well as things.

The Zeitgeist over the past several decades has been that these competencies - language and cognition-are separate systems. However, in recent years Whorf's (1956) claim that the language we speak influences the way we think has again attracted attention (see Gentner and Goldin-Meadow 2003; Gumperz and Levinson 1996; Levinson 2003) after decades of ill favor. The extreme Whorfian hypothesis that language determines a speaker's perception of the world has given way to more constrained versions of the question, as described below. ${ }^{1}$ In addition to asking whether adult speakers of different languages think differently, research is also addressing effects of language within a language during cognitive development in children and adults our main concern here.

In this paper we develop three claims as to 'why we're so smart.' The first is that analogical processes contribute in specific ways to cognitive development. The second claim is that possessing a human language-especially relational language - substantially augments our relational ability. The third is that relational ability is crucially involved in language learning, especially in learning relational terms and grammatical constructions. This results in a positive feed-

1. Whorf himself also considered more constrained versions of the language and thought. Along with his stronger conjectures about the role of language in thought, Whorf (1956: 239) also wrote, "My own studies suggest, to me, that language, for all its kingly role, is in some sense a superficial embroidery upon deeper processes of consciousness, which are necessary before any communication, signaling, or symbolism whatsoever can occur ..." 
back system: our relational ability permits us to learn language, and the acquisition of language augments our relational ability.

Our view is that language provides tools for cognition. According to this view, dubbed the language as cognitive toolkit view by Gentner and GoldinMeadow (2003), language provides new representational resources that augment human cognitive capacities; but it does not replace other encoding formats (Gentner 2003; Gentner and Goldin-Meadow 2003; Loewenstein and Gentner 2005; see also Frank et al. 2008; Wolff and Holmes, in press). Our assumption is that humans are pluralistic thinkers, and other modes of thought, such as spatial imagery or qualitative estimation, coexist with our linguistically influenced thinking. Thus, the toolkit view should be distinguished from the strong linguistic determinism view often attributed to Whorf. We also do not assume that all thinking is done by internal speech. Nonetheless, language plays a large role in our account of human cognition.

Our central claim is that language invites and makes accessible representations that can then be used more generally, with or without the conscious use of internal language. This position draws on both Whorf (1956) and Vygotsky (1962), as well as on more recent accounts (Boroditsky 2009; Gumperz and Levinson 1996; Hunt and Agnoli 1991; Slobin 1991). It is consistent with Carey's (1985) proposal that an important factor in cognitive development is that children acquire "tools of wide application" that facilitate forming particular representations and carrying out particular processes. Applied to cognitive development, the toolkit view predicts that acquiring language can influence children's ability to represent and reason.

We first review analogical processing, including its role in learning. Then, we describe some important ways in which analogical processing enters into language learning, especially the acquisition of relational language. Then, we turn tables and discuss how language promotes and supports analogical processing. Finally, we discuss a case in which analogy and language work in close tandem - namely, the acquisition of number words and the idea of cardinal number.

\section{How analogical processing fosters learning}

According to structure-mapping theory (Gentner 1983), comparison takes place via a structure-mapping process that finds a structural alignment between two represented situations and then projects inferences consistent with that alignment. The alignment process is guided by a set of tacit constraints that lead to structural consistency: a) there must be one-to-one correspondence between the mapped elements in the target and base, and b) there must be parallel connectivity (i.e. if two predicates correspond, then their arguments must correspond as well). A central characteristic of analogy and similarity 
comparisons is systematicity: a bias for interpretations in which the lowerorder matches (such as events) are connected by higher-order constraining relations (such as causal or mathematical relations). The systematicity principle captures a tacit preference for coherence and predictive power. Thus, when a given analogy affords more than one consistent interpretation, people prefer the more systematic interpretation, all else being equal (Clement and Gentner 1991). ${ }^{2}$ Further, if given two examples to compare, people tend to choose the one with deeper causal or explanatory structure as the base domain, and use it to structure the less systematic case (Bowdle and Gentner 1997). As a natural outcome of the alignment process, candidate inferences are projected from the base to the target. These inferences are propositions connected to the common system in one analog, but not yet present in the other.

An advantage of the systematicity preference is that it biases in the direction of deep structural alignments without the need for advance knowledge of the point of the comparison. (A process that requires advance knowledge would be implausible as an account of developmental learning.) In fact, however, structural alignment can be realized with a process that begins blind and local, as long as it has a bias for matching predicates that are relationally connected over independent matches (i.e. for systematicity in matching). For example, the Structure-Mapping Engine (SME) utilizes an alignment process that begins with purely local matches and culminates with one or a few deep, structurally consistent alignments (Falkenhainer et al. 1989; Forbus et al. 1995).

Achieving a structural alignment sets the stage for four kinds of learning3: abstraction, re-representation, inference-projection, and difference-boosting. In abstraction, the common system resulting from the alignment becomes more salient and more available for future use (Figure 1a) (Gentner 1983; Gick and Holyoak 1983; Markman and Gentner 1993a; Namy and Gentner 2002). In re-representation, two non-identical relations are re-represented to permit the overall match. This occurs when there is reason to believe that a match is possible, and that there would be a greater alignment if they matched (Gentner and Rattermann 1991; Yan et al. 2003). Inference-projection occurs when one member of the pair is more complete in its structure than the other; in this case, spontaneous candidate inferences will be made that enrich the less-complete item (Figure 1b) (Bowdle and Gentner 1997; Clement and Gentner 1991). Fi-

2. In addition to systematicity, two other criteria enter into the choice of an interpretation: the factual correctness (or falsity) of the inferences in the target; and the contextual relevance of the interpretation, and its inferences.

3. Analogy is also a major contributor to another form of knowledge change, namely, restructuring - altering the domain structure of one domain in terms of the other. This is a true case of conceptual change in Carey's (1985) sense. However, true restructuring almost certainly requires more other processes in addition to analogy (Dunbar 1995). 


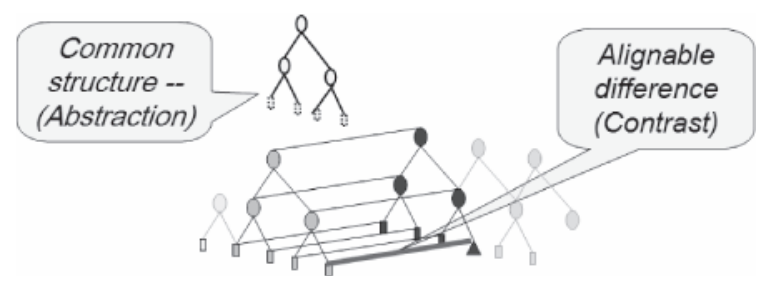

(a)

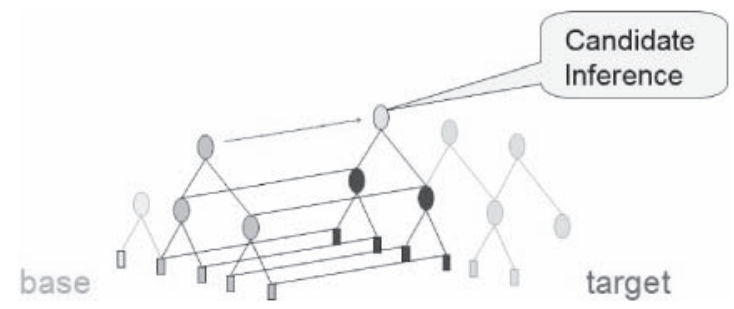

(b)

Figure 1. Comparison as Structure-mapping. (a) Structural alignment promotes abstraction of common structure and highlights alignable differences. (b) Structural alignment supports the projection of candidate inferences.

nally, in difference-boosting, alignable differences-differences that occupy the same role in the two systems - are highlighted (Figure 1a) (Gentner and Markman 1994; Markman and Gentner 1993b).

In this paper we focus on the first three subprocesses - abstraction, rerepresentation, and inference-projection-leaving aside difference-boosting. Before presenting empirical evidence, we first illustrate these three subprocesses with an illustrative example comparison:

Wallcorp divested itself of Best Tires.

Likewise, Martha divorced George.

Students presented with this pair readily form a common abstraction: "Both got rid of something they no longer wanted." To form this abstraction requires not only aligning the two statements but re-representing the relations to arrive at the common relation got rid of something they no longer wanted. This kind of re-representation via minimal ascension to a common relational superordinate is common in analogical abstraction.

To observe the analogical inference process, we then give a bit more information about the base situation (Walcorp):

Wallcorp divested itself of Best Tires and bought a more profitable tire company.

Likewise, Martha divorced George, and ... 
Students almost always infer that Martha married a new husband who is richer, more handsome, or more powerful than the previous one. Note that they don't infer that she bought a tire company; their inferences are structurally governed. That is, what is projected is not a specific fact (bought a tire company after selling another) but, rather, the relation of replacing something (a tire company or a husband) with a more profitable or better instance of the same category. This is because inference projection (like other analogical processes) preserves relations, insofar as possible, but substitutes corresponding objects. Since the current tire company corresponds to the current husband, the inference is that the current husband was replaced by a more profitable member of the husband category. Most people given this analogy re-represent the more-profitable-than relation as better than, which they then may further specify to fit the target (e.g. "someone richer or handsomer").

As this example suggests, adults can readily extract common relational structure from a comparison and draw further inferences, even when the match requires some re-representation. We have found that comparison can foster abstraction and a degree of re-representation in children. As we will discuss, many studies bear out the claim that comparison makes common relational structure more salient to children. However, when considering children's learning, we need to take seriously the fact that young children do not have anything close to a complete stock of relational knowledge. Thus they are often unable to make purely relational mappings. Left to their own devices, preschool children often focus on object commonalities; after all, they often have good knowledge of how things look. For example, a 4-year-old asked "How is a plant stem like a drinking straw" responds "Both are long and thin," and rejects the response (when offered in a quiz show format) that "Both bring water to something that needs it" (Gentner 1988). A 9-year-old, in contrast, prefers the relational match over the match in object properties - a change that Gentner (1988) termed the relational shift ${ }^{4}$.

At first glance, the above discussion seems to lead to the conclusion that structural alignment can occur only after children have mastered the relevant relations - a conclusion that would largely obviate its value in early learning. However, there is a technique that can bootstrap children's relational encoding in a domain, namely, progressive alignment. In progressive alignment, children are first given close, concrete comparisons and then given more abstract, purely relational comparisons involving the same relational structure (Kotovsky and Gentner 1996). In a close similarity comparison, the object matches-

4. This shift may be due in part to increases in processing capacity (Halford 1992) or in executive function (Richland et al. 2006); however, we maintain that a major cause of the shift is increases in relational knowledge, including that gained through language (Gentner and Rattermann 1991). 
which are easy for the child to grasp - support the correct structural alignment. Because the structure-mapping process favors common relations, achieving a structural alignment — even between a highly similar pair — will increase the salience of the common relational structure somewhat. This in turn increases the likelihood that the child will subsequently be able to align the early examples with a further, less surface-similar instance of the same relational structure. Many studies have borne out these predictions (Gentner et al. in press; Gentner et al. 2007; Kotovsky and Gentner 1996; Loewenstein and Gentner 2001; Namy and Gentner 2002; Thompson and Opfer, in press; Waxman and Klibanoff 2000). We exemplify progressive alignment below.

With these preliminaries in place, we now turn to analogical processes in language learning. To preview, there is increasing evidence that comparing exemplars is an important part of the process by which learners arrive at word meanings.

\section{How analogical processing supports language learning}

Comparison in relational learning. Comparison across exemplars plays an important role in children's acquisition of word meaning (Childers 2008; Gentner and Namy 2004). For example, Gentner and Namy (1999; Namy and Gentner 2002) found that children were more likely to extend a new word on the basis of conceptual commonalities (as opposed to purely perceptual commonalities) when they compared two instances of the standard than when they saw only one (See also Liu et al. 2001). A striking example of the power of comparison comes from a study by Christie and Gentner (in press), who taught 3- and 4-year-old children names for novel spatial relations and asked them to extend the name to another instance. Three-year-olds given one standard chose $98 \%$ of the time on the basis of matching objects, disregarding the spatial configuration. Those who had compared two standards chose the matching relational configuration (with new objects) $57 \%$ of the time. In other words, the comparison group was roughly 25 times more likely to choose on the basis of relations as was the solo group.

Comparison is particularly effective at highlighting the relational information necessary for learning verbs and other relational terms (Childers in press; Childers and Paik 2009; Gentner and Namy 2004; Haryu, Imai, and Okada in press; Pruden et al. 2008). For example, Childers (in press) found that $2 \frac{1}{2}$ -year-olds were better at learning novel verbs if they compared multiple instances that varied in their specific details. When young children are unable to align highly variable exemplars, progressive alignment can help them learn. For example, Haryu et al. (in press) found that Japanese 3- and 4-year-olds were successful in learning a new verb meaning from multiple exemplars when 
the events all involved similar objects (making them highly alignable), but less successful when the events involved different-looking objects.

A second study showed effects of progressive alignment. The progressive alignment group was first given four trials of the verb with highly similar objects, and then four trials with highly dissimilar objects; the control group received an equal number (eight trials) with dissimilar objects. As expected, the progressive alignment group was more successful on the first four (all similar) trials than was the control group. But the important finding concerns the last four trials, in which both groups received dissimilar objects. The progressive alignment group did far better than the control group: whereas the control group performed at chance $(50 \%)$ throughout, the progressive alignment group was $86 \%$ correct on the last four trials. This pattern parallels findings by Gentner et al. (2007) for 3-year-olds' learning of new body-part terms.

\section{How language augments analogical processing}

Recent studies have found evidence for a variety of ways in which language may support conceptual learning and processing. In keeping with our theme, we focus specifically on ways in which language enters into analogical processing. We suggest four specific ways in which language influences the structure-mapping process (Gentner 2003; Gentner and Loewenstein 2002):

(1) Common labels invite comparison and abstraction: By giving two things the same name, we invite children to compare them; the implicit message is that the two things share some commonalit(ies) that matter (Gentner and Medina 1998; Gentner and Namy 1999, 2004; Christie and Gentner, in press). The common system that results from this comparison will be more salient than before, and may form the seed for a new category (Gentner and Namy 1999; Kotovsky and Gentner 1996). Further, the abstraction process often requires some re-representation of the relations to render them applicable to both situations. This more abstract encoding renders the relation more portable to other contexts.

(2) Naming promotes reification: A linguistic label confers stability on the abstraction gained from a comparison, making it more likely to be retained and accessed in the future (Gentner 2003; Lupyan et al. 2007; Xu 2007). Another advantage of reification, besides memory accessibility, is that it facilitates making new assertions about that abstraction. A named relational schema can serve as an argument to a higher-order proposition. For example, consider this sentence from the New York Times Book Review "The economic adversity caused by droughts or floods far exceeds the direct impact on the food supply." The economy made possible by the relational nouns adversity, drought, flood, and impact, and the higher-order connecting relations cause and exceed, makes 
it possible to state a complex embedded proposition compactly. Expressing complex assertions like the above would be prohibitively awkward without such relational compaction.

(3) Naming promotes uniform relational encoding: This point is related to point (1) - comparison, abstraction and re-representation. Common labels invite children to abstract a relational structure away from the initial context, and, often, to re-represent the initial relations to arrive at a (slightly) more abstract relation. Such a relation will be more widely applicable than the initial more specific relations, potentiating a more uniform relational vocabulary. The idea of uniform relational encoding is also related to point (2) - reification. The idea is that naming a relation promotes its re-use, and habitual use of a given relational term promotes encoding the relation in the same manner in different contexts.

Why does uniform relational encoding matter? We theorize that it is a determinant of relational transfer (Forbus et al. 1995). Relational transferretrieving a prior situation that shares relational structure with the current situation - is generally quite poor (compared to retrieval based on surface matches), even for adults who have no trouble recognizing the relational match when both items are present (Gentner et al. 1993; Gick and Holyoak 1980; Ross 1987). We suggest that this is in part because relational information is typically encoded in a more context-dependent manner than is object information (Asmuth and Gentner 2005; Gentner 1981c; Gentner and France 1988). To the extent that people encode relations in a uniform manner across many contexts, they should show higher relational retrieval. Indeed, Forbus et al. (1995) speculated that one reason experts show better relational retrieval than novices (Novick 1988) is that they habitually use a stable system of concepts (acquired in part by reification of technical terms in the domain). This uniform relational encoding increases the likelihood of relational reminding, because it increases the likelihood that a new situation will be construed according to the same relational schema as prior experiences. The growth of technical vocabulary is thus both a symptom and a cause of increasing expertise.

(4) Linguistic structure invites conceptual structure: Systematic structure in the language can invite correspondingly systematic conceptual structure (Carey 2004, 2009; Loewenstein and Gentner 2005). As one instance, lexical contrast may sometimes invite parallel conceptual contrast. For example, in Carey and Bartlett's (1978) fast-mapping study, children were shown two objects and asked to give "the chromium one, not the red one." This linguistic contrast invites the inference that chromium and red belong to the same category, but are not identical. Because of the one-to-one correspondence between objects and words, this structure can be mapped to the two objects, permitting the child to infer which one is the chromium one, and (at least for some 
children) what chromium means. We discuss two more extensive examples below, one from spatial language and one from number language, illustrating how language learning can drive conceptual learning.

The above subprocesses are not specific to relational language; they apply to entity terms as well. For example, calling things by the same name leads children to co-categorize them (Smith et al. 1992; Waxman and Markow 1995); and in adult learning, Lupyan et al. (2007) found that categories labeled by nouns were learned faster than unlabeled categories, even though the labels did not convey additional information. Xu's (2007) studies suggest further that learning names for object categories helps infants reify the categories. She finds that 10-month-olds are better at keeping track of two different kinds of objects (e.g. a truck versus a duck) if they already have names for them.

We suspect that the effects of knowing linguistic labels is likely to be even greater for relational concepts (such as motion events or spatial relations) than for concrete entity concepts (such as object categories), because relational concepts - both verbs and nominal relations such as brother - are in general slower to be learned by children and harder to retain in memory by adults, as compared to entity concepts (Gentner 1982, 2005, 2006; Gentner and Boroditsky 2001; Golinkoff and Hirsh-Pasek 2008; Hirsh-Pasek and Golinkoff 2006). Thus they have more to gain from reification. Due to space constraints, we will not go through the evidence here, except to note that the full meanings of nominal relational categories such as brother are acquired relatively late, and are often initially taken to be entity categories (i.e. defined by intrinsic properties). Thus, a four-year-old may believe that brother means a boy with freckles, and only later grasp its relational meaning (Clark 1973). Observing uses of the term "brother" over time provides evidence against the simply entity interpretation. Further, if the term is used for two exemplars that the child is able to compare (as discussed below), this can help the child discover the relational interpretation. We next review evidence for the claim that language augments analogical processing.

\subsection{Comparison and abstraction}

To paraphrase Roger Brown (1973), a common label is an invitation to compare two things. This 'invitation to compare' is important in children's learning. As discussed above, comparison is a good way - in some cases the only viable way - to arrive at a new relational abstraction. But young children do not spontaneously compare two things (in the absence of a common label) unless the two things look very similar and occur in close juxtaposition. Thus, a young child will spontaneously compare a chicken with a turkey, but without the aid of a common label bird, the child may not spontaneously compare either of these to a robin. By giving two things the same name, we invite children 
to compare them, whether or not they look alike and whether or not they occur in immediate juxtaposition. Gentner and Medina (1998) refer to this as symbolic juxtaposition.

An example of language as an invitation to compare is a study by Casasola on infant learning of the spatial relational term on. The English on encompasses a range of events, from a Lego tightly fitted on top of another Lego to a little doll standing on a toy car (events that would be classified as tight-fit and loose-fit, respectively, in Korean) (Bowerman and Choi 2003; see also Gentner and Bowerman 2009). A study by Casasola (2005) showed that 18 -month-old English-speaking infants were able to induce this abstract category of support from disparate examples, but only when they heard the word on during habituation trials. Infants in this study were all habituated to four support events - two tight-support and two loose-support events, all with rather dissimilar objects. Infants then viewed four test events in sequence: familiar objects in the familiar on relation (i.e. a repeat of a habituation event); new objects in the familiar on relation; familiar objects in a new relation (in-i.e. containment); and new objects in a new relation (in). The results were striking. Infants who had heard general language ("Look at that!") during habituation failed to notice the change in relations; they only noticed a change in objects. In contrast, infants who had heard the spatial word on during habituation looked longer at events involving the new relation, in, with both familiar and new objects, indicating that they had formed an abstract representation of the support relation. We suggest that repeating the term on across the study items invited comparison, which fostered the abstraction of the support relation. It may also have invoked children's prior experience with the term, consistent with the second theme, reification.

\subsection{Reification}

Labeling a pattern of relations with a linguistic term helps to fix that pattern in memory, making it more accessible in memory and increasing the likelihood that the learner will perceive the pattern again across different circumstances. The most obvious instance of this increased accessibility is that a named pattern can be re-invoked by using the name. For example, Simms and Gentner (2008) have found that preschoolers are better able to solve a 'treasure hunt' search task where the rule is to look exactly between two landmarks if they are reminded of the term "middle" during the task. Although we take this for granted, it is worth noting that calling forth a conceptual structure at will simply by using its name is an essential aspect of the human power to reason about the "there and then" instead of only the "here and now." But linguistic labels have effects beyond their direct use in invoking concepts, as illustrated by the following results. 


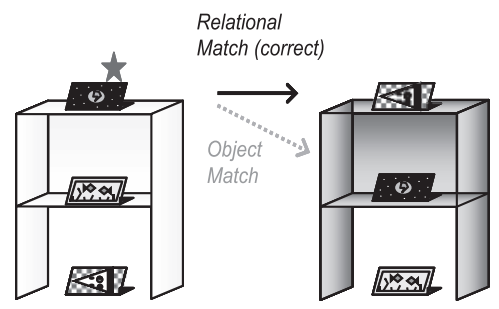

(a)

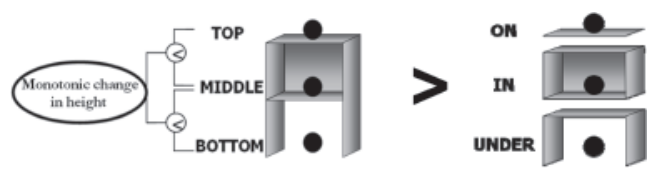

(b)

Figure 2 (a) Task used in Loewenstein and Gentner (2005). (b) The set of terms top, middle, bottom conveys more systematic structure than set of terms on, in, under. This systematic structure facilitates mapping the correct relational match in task (2a).

Recent evidence for the benefit of spatial relational language was offered by Loewenstein and Gentner (2005) in a spatial mapping study. Preschool children saw two identical three-tiered boxes; they watched the "winner" being placed in one box (the Hiding box) and then searched for their own "winner," which was always in the same relative location in the Finding box (see Figure 1a). Children performed better when the Hiding box was described using spatial relational terms such as on, in, under or top, middle, bottom. For example, in one study the experimenter began by saying "We're going to play the on, in, under game" and asked the child to point to the three locations in the Hiding box. The control group simply pointed back and forth between the boxes, without hearing any specific spatial language. The hide-and-find task was identical for the two groups: the experimenter told the children that they could find their winner "in the same place" as the Hiding winner. Then on each trial, she simply said "I'm putting it here" as she placed the winner in the Hiding box.

Not only did children perform better initially when given spatial language, but they retained the spatial pattern better. In one study, children were brought back to the lab two-to-four days after completing the spatial mapping task and were shown a somewhat altered set of boxes. All children-whether in the language group or the control group - were simply asked to "play the same game again." Children who had initially received relational language performed significantly better than those who had not (Loewenstein and Gentner 2005), suggesting that hearing the spatial relational terms not only invited chil- 
dren to represent the two boxes in a spatially delineated way, but helped them retain this representation.

\subsection{Structure: Linguistic structure invites corresponding conceptual structure}

As just reviewed, a relational term — such as middle, or opposite, or parallel can invite attention to a relational construal of a situation, rather than to the objects - a construal that may be advantageous for certain purposes. One particularly powerful kind of relational construal is a systematic representation: that is, one in which the lower-order relations are interconnected by a higherorder constraining relation. We illustrate this by returning to the Loewenstein and Gentner (2005) study discussed above (see also Gentner and Rattermann 1991). Recall that children performed better when given spatial terms - either top, middle, bottom or on, in, under-describing the three locations. But these two sets of terms differ in an important way: top, middle, bottom forms a systematic structure governed by the higher-order relation of monotonicity in the vertical dimension; in contrast, on, in, and under each describe a figure-ground relation (see Figure 1b). When the box-mapping task was made more difficult by introducing a competing object match (a cross-mapping, Gentner and Toupin 1986), children performed far better at the spatial mapping task when given the terms top, middle, bottom than when given the terms on, in, under, which lack a unifying higher-order structure. We suggest that hearing top, middle, bottom invited a conceptual representation of the monotonic spatial relational structure of the two boxes. This higher-order structure helped the children to resist the tempting object matches and achieve a relational mapping. Here, then, is an example of the contribution of language to analogical processing.

Finally, if language instills enduring delineated representations of spatial relations, then we would expect children who lack such input to be at a disadvantage in tasks requiring the representation. Using the same spatial mapping paradigm (the box task), a recent study in Istanbul compared 5-year-old children who were learning Turkish at a typical rate with deaf children whose hearing losses had prevented them from learning a spoken language and who had not been exposed to a sign language. The deaf children used gestures, called homesigns, to communicate with the hearing individuals in their worlds. Importantly, although homesign contains many of the linguistic properties found in early child language (Goldin-Meadow 2003a), the homesigns invented by Turkish deaf children do not contain gestures for or other linguistic means of conveying spatial relations (Gentner et al. 2008). The Turkishspeaking hearing children were matched to the homesigning deaf children on a representative spatial cognition task (spatial transformation), and all children 
were given the box task without spatial language. The hearing children, all of whom had a good command of Turkish spatial terms, performed far better on the task than the deaf children. Gentner et al. suggest that the deaf children, lacking a stable system of terms for spatial relations, were less likely to represent the arrays in the two boxes in a uniform way, and therefore less able to align them.

We have reviewed evidence for the mechanisms discussed above by which language influences children's cognitive development: that common labels invite comparison and abstraction (Gentner et al. in press; Gentner and Namy 1999); that labels can induce a stable enduring representation (Casasola 2005; Loewenstein and Gentner 2005); and that structured language invites a structured representation (Loewenstein and Gentner 2005). Most of these examples have come from the domain of spatial language. Now we turn to the domain of number for an example that illustrates how language and analogical processing interact to bootstrap cognitive development.

\section{Bootstrapping number}

\subsection{Language enters into the understanding of number}

Intuitively, mathematical structure seems so compelling that it must be an inevitable discovery of human development. The French mathematician Charles Hermite believed "that the numbers and functions of analysis are not the arbitrary product of our spirits; I believe that they exist outside of us with the same character of necessity as the objects of objective reality ..." (quoted in Dehaene 1997 p. 242). Yet there is evidence that even simple numerical insight is not inevitable, and that language plays a role in supporting numerical cognition. For example, Spelke and Tsivkin (2001) found that Russian-English bilinguals who were trained on exact calculation problems in one language deteriorated sharply when asked to do similar problems in their other language. Yet when trained on approximation problems (which presumably do not depend on language), the bilinguals could readily transfer from one language to the other. This pattern led Spelke and Tsivkin to suggest that language is instrumental in the representation of exact number.

An account of the acquisition of number must begin with two preverbal capacities that have been implicated in accounts of number development: the analog magnitude system and an object-tracking system. The analog magnitude system, a system shared broadly with other species, allows approximate judgments of quantity and is often modeled with an accumulator model (Meck and Church 1983; Gallistel and Gelman 1992). This skill operates over even very large quantities, but its accuracy is limited by Weber's Law: the discriminability between two amounts is a function of their ratio. Thus, inaccuracies 
occur for magnitudes that are very close. The object-tracking system keeps track of small numbers of items. It is part of our general ability to represent mental models of the world (Carey 2004; Spelke 2000). In contrast to the analog magnitude system, the object file system operates over discrete representations and is capacity-limited, to roughly three or four objects.

Dramatic evidence that number language augments these preverbal capacities comes from studies of two Amazonian peoples whose languages - Pirahã and Mundurukú - lack a full counting system (Frank et al. 2008; Gordon 2004; Pica et al. 2004). In his pioneering studies, Gordon (2004) investigated the Pirahã, whose language for numbers can be described as "one, two, many. 5 ", Gordon gave a variety of simple numerical tasks to Pirahã participants and found striking failures even on (apparently) simple tasks. For example, participants were shown an array of nuts for 8 seconds, after which the nuts were put into a can. Then the experimenter took out the nuts one by one, each time asking participants whether the can still contained nuts or was empty. The Pirahã were fairly accurate for amounts of three or fewer, but were only approximately correct for large numbers (Gordon 2004). This basic pattern was replicated by Frank et al. (2008) working with the Pirahã, and by Pica et al. (2004) working with the Mundurukú. All three of these studies found greater inaccuracies for larger numbers - a signature of the analog magnitude system. Pica et al. also compared French speakers with Mundurukú speakers on a set of numerical tasks, and found that the Mundurukú were comparable to French speakers on numerical estimation tasks, but greatly deficient on tasks that require exact numbers beyond two or three. It appears that language profoundly influences numerical cognition, consistent with the tool kit account. However, and again consistent with the tool kit account, language does not replace the preverbal capacity for magnitude estimation (see also Frank et al. 2008).

\subsection{A momentous analogy: Learning the linguistic count list invites corresponding numerical structure}

What are the mechanisms by which language might influence development of number? One fascinating possibility is that the ordered counting routine serves as an analogy that invites children to organize numerical quantities into an ordinal sequence (Carey 2004, 2009). Under this account, children first learn the counting routine as a kind of language game, with only a vague connection to numbers. At this stage, a typical 2-year-old may be quite proficient at counting

5. However, it now seems likely that the correct interpretation of the Pirahã terms is "few, more, even more," in which case they would entirely lack terms for numbers. Frank et al. (2008) found that the Pirahã assigned their quantity terms differently when they named quantities beginning with 10 and worked down to 1 than when they named them from 1 to 10 . 
from 1 to 10, while at the same time showing little or no insight into cardinality. Such a child can readily count to four, but if asked to "show me four marbles" will produce three, five, or eight marbles (Fuson 1988; Wynn 1990). Even when a young child has just correctly counted a set of objects (" $1,2,3,4$ "), she typically cannot respond "four" to the question "So how many are there?"

Gradually, the child learns to attach number words to very small set sizes, which can be tracked by the object tracking system. The learning is at first slow and piecemeal - even after binding two to sets of cardinality two, weeks or months may ensue before the child realizes that three refers to a set with three items (Mix 2002; Mix et al. 2005; Carey 2004). But once a child reaches an understanding of roughly three or four, the pattern changes. The child rapidly binds the succeeding numbers to their cardinalities. According to Carey (2004, 2009) the child at this point has grasped the analogical mapping between the linguistic number sequence and the conceptual sequence of whole-number set sizes: counting one further in the count sequence maps onto increasing by one in the set size. At this point the child will also show understanding of the successor principle, that every (natural) number has a natural successor: more specifically, "If number word X refers to a set with cardinal value n, the next number word in the list refers to a set with cardinal value $n+1$ " (Carey 2004) (but see Rips et al. (2008) for a different account).

Of course, the analogy of parallel increase between counting one further in the count sequence and adding one in quantity is quite abstract. It requires mapping from a linguistic representation ordered in time, supported chiefly by auditory input, to a representation ordered in quantity, supported chiefly by visual input. Consistent with general patterns in analogical development (Gentner and Medina 1998), children's first forays into the mapping between number and set size are local and context-specific (Mix 2002; Mix et al. 2005). For example, in Mix's (2002) diary study, at 20 months Spencer spontaneously brought from another room exactly two treats for the family's two dogs, and repeated this feat with perfect accuracy several times over the next few weeks. But his understanding of "twoness" was highly context-bound; he failed when asked to go get "train treats" for his two toy trains.

Mix and colleagues suggest that hearing two sets labeled with the same count word prompts a comparison process that leads the child to notice their common number (Mix et al. 2005). This is consistent with our first claim, that common labels invite comparison and abstraction. Thus, hearing the count label "three" applied to three apples, three pigeons, and so on may prompt comparison across the sets and abstraction of their common set size. Number language also appears to help reify and stabilize numerical representation so that exact numbers become available for use at will — as evidenced by the difficulties experienced by Pirahã speakers as compared to English speakers, and even by Russian speakers calculating in their second language, as compared to 


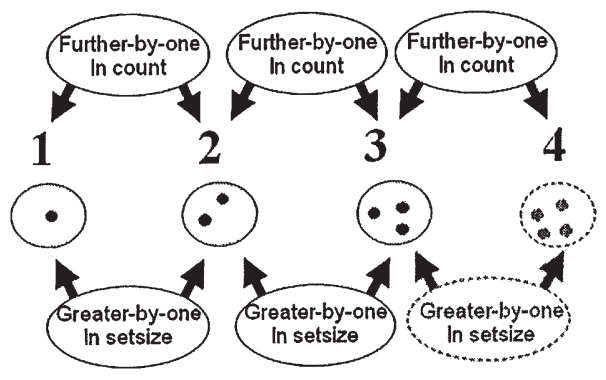

(a)

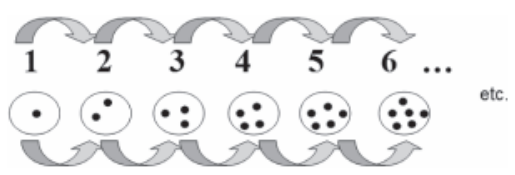

(b)

Figure 3. The analogy linking count sequence and numerical order (based on Carey's (2004, 2009) proposal). (a) When the child has "2" connected to set size 2 , and " 3 " to set size 3 , this makes two instances of the same relational pattern-permitting an analogy. This analogy invites the candidate inference that the same relational pattern will hold for "4": that is, that its set size will be one greater than the set size of "3."

(b) The analogy also invites the abstraction IMPLIES \{FURTHER-BY-ONE (count list), GREATER-BY-ONE (set size)\} -i.e. the idea that the sequence continues indefinitely.

the same speakers calculating in their first language. Finally, as the "parallel increase" analogy shows, number language provides an elegant ordered structure that can be mapped onto conceptual structure.

The parallel increase analogy from number language to quantity offers a striking case of the power of systematic language to confer systematic conceptual structure. But this example also underlines the importance of analogical ability in reaping the potential power of a symbolic structure. Only when the child aligns the few examples in her repertoire and notices the common relational pattern that holds across 1,2 , and 3 can she make the inference that the same pattern might hold for 4 , and even beyond. This is a quintessential case of the ratcheting of analogical ability with symbolic structure to create insight.

The available evidence suggests that both number language and analogical ability are needed for this feat. The findings discussed above on the Pirahã and the Mundaruku suggest that humans lacking numerical language do not (or not typically) arrive at this insight. The Pirahã deal with quantities in their ordinary life, but they seem to represent them only in terms of approximate relative magnitude. Turning to the other side of the feedback loop, what if one 
possesses number language but not great analogical prowess? For this we turn to chimpanzees, our closest cousins evolutionarily.

5.2.1. Relational ability across species. There is evidence that a major difference - perhaps the major difference — in cognitive ability between our species and the other great apes is that we greatly exceed the other apes in relational ability (Gentner 2003; Gentner and Christie 2008; Haun and Call 2009; Penn et al. 2008). For example, although chimpanzees readily learn an object match-to-sample task (given A as standard, choose alternative A rather than B), they have great difficulty learning a relational match-to-sample task (given AA as standard, choose alternative BB rather than CD) (Oden et al. 2001; Premack 1983) - a task that human children can master before five years of age (Christie and Gentner 2007).

Interestingly, these highly intelligent animals can learn and use numbers up to around 8 (Boysen et al. 1996). For example, chimpanzees in Boysen's study could point to the correct Arabic numeral when given a set of items, and could point to a set of objects when given a numeric symbol. Yet, there is no evidence that they ever experienced the analogical insight that the same parallel-increase pattern occurs over and over. ${ }^{6}$

\section{Concluding remarks}

The view of language effects taken here is in some ways an amalgam of the Whorfian view and the Vygotskian view. We accept Vygotsky's account that language, though initially acquired socially, becomes an internal resource on which children can draw. But Vygotsky's emphasis was on the power of language qua language; he emphasized the role of inner speech in establishing volitional control, planning abilities, and so forth. On this point, our language as cognitive toolkit view is more aligned with the (moderate) Whorfian position that the specific semantics and grammar of a language influence the cognitive conceptions of its speakers.

The re-representation process we describe may be relevant to KarmiloffSmith's (1992) idea of representational rediscription. Her account of how the accumulation of experience leads to conceptual change is very appealing, but it has the somewhat mysterious feature that representational redescription occurs after mastery is reached. The question is what in particular compels such a redescription. We suggest that as learners accumulate experience in a domain,

6. Of course, this could simply stem from specific aspects of the way chimpanzees are taught language. Unlike children, chimpanzees are not taught to chant the numbers; and unlike children, who typically hear numbers like "50," "100," and above, chimpanzees may not receive much evidence that the count string goes on indefinitely. 
they begin to compare like pairs; each such comparison slightly increases representational uniformity, at least at a local level. As domain learning continues, comparisons become increasingly likely (both because the density of exemplars increases and because prior comparisons will have already led to greater uniformity). These smaller steps may set the stage for a more global representational redescription.

There remain many open questions. Perhaps chief among them is how it all gets started: Is there a stock of innate relations that seeds the first analogies? If so, what might they be? And do they initially show up as primitive components that later combine with other primitives? Or are these $u r$-relations instead highly concrete and context-specific? Researchers are only beginning to take on these questions (e.g. Doumas et al. 2008).

We have reviewed evidence for a feedback system in which analogical processes support the acquisition of language, which in turn supports more sophisticated analogizing. On this account, language serves as a cognitive tool kit that amplifies our inherent abilities. We considered four ways in which language supports relational cognition: by inviting comparison and abstraction, by fostering reification, by promoting uniform relational encoding; and by providing systemic linguistic structures that can invite and support parallel conceptual structures. We conclude by noting that this fruitful partnership between analogy and language does not end with childhood. We continue to use analogical processes - often invited by language - to learn new concepts and to re-represent old ones throughout adulthood.

\section{References}

Asmuth, J. \& D. Gentner. 2005. Context sensitivity of relational nouns. Proceedings of the 27th annual meeting of the Cognitive Science Society. 163-168.

Boroditsky, L. 2009. How does our language shape the way we think? In Brockman (ed.), What's next? Dispatches on the future of science. Vintage Press.

Bowdle, B. \& D. Gentner. 1997. Informativity and asymmetry in comparisons. Cognitive Psychology 34(3). 244-286.

Bowerman, M. \& S. Choi. 2003. Space under construction: Language-specific spatial categorization in first language acquisition. In D. Gentner \& S. Goldin-Meadow (eds.), Language in mind: Advances in the study of language and cognition, 387-428. Cambridge, MA: MIT Press.

Boysen, S. T., G. G. Berntson, M. B. Hannan \& J. T. Cacioppo. 1996. Quantity-based interference and symbolic representations in chimpanzees (Pan troglodytes). Journal of Experimental Psychology: Animal Behavior Processes 22(1). 76-86.

Brown, R. 1973. A first language: The early stages. Cambridge, MA: Harvard University Press.

Carey, S. 1985. Are children fundamentally different kinds of thinkers and learners from adults? In S. F. Chipman, J. W. Segal \& R. Glaser (eds.), Thinking and learning skills 2, 485-517. Hillsdale, NJ: Lawrence Erlbaum Associates.

Carey, S. 2004. Bootstrapping and the origin of concepts. Daedalus 133.

Carey, S. 2009. The origin of concepts. New York: Oxford University Press.

Carey, S. \& E. Bartlett. 1978. Acquiring a single new word. Papers and Reports on Child Language Development 15. 17-29. 
Casasola, M. 2005. Can language do the driving? The effect of linguistic input on infants' categorization of support spatial relations. Developmental Psychology 41. 183-192.

Childers, J. B. 2008. The structural alignment and comparison of events in verb acquisition. In V. S. Sloutsky, B. C. Love \& K. McRae (eds.), Proceedings of the 30th annual Cognitive Science Society. Austin, TX: Cognitive Science Society.

Childers, J. B. In press. Attention to multiple events helps $2 \frac{1}{2}$-year-olds extend new verbs. First Language.

Childers, J. B. \& J. H. Paik. 2009. Korean- and English-speaking children use cross-situational information to learn novel predicate terms. Journal of Child Language 36(01). 201-224.

Christie, S. \& D. Gentner. 2007. Relational similarity in identity relation: The role of language. In S. Vosniadou, D. Kayser, \& A. Protopapas (eds.). Proceedings of the second European cognitive science conference, 601-666. London: Taylor and Francis.

Christie, S. \& D. Gentner. In press. Where hypotheses come from: Learning new relations by structural alignment. Journal of Cognition and Development.

Clark, E. V. 1973. What's in a word? On the child's acquisition of semantics in his first language. In T. E. Moore (ed.), Cognitive development and the acquisition of language, 65-110. New York: Academic Press.

Clement, C. A. \& D. Gentner. 1991. Systematicity as a selection constraint in analogical mapping. Cognitive Science 15. 89-132.

Dehaene, S. 1997. The number sense: How the mind creates mathematics. New York: Oxford University Press.

Doumas, L. A. A., J. E. Hummel \& C. M. Sandhofer. 2008. A theory of the discovery and predication of relational concepts. Psychological Review 115. 1-43.

Dunbar, K. 1995. How scientists really reason: Scientific reasoning in real-world laboratories. The Nature of Insight. 365-395.

Falkenhainer, B., K. D. Forbus \& D. Gentner. 1989. The structure-mapping engine: Algorithm and examples. Artificial Intelligence 41. 1-63.

Forbus, K. D., D. Gentner \& K. Law. 1995. MAC/FAC: A model of similarity-based retrieval. Cognitive Science 19. 141-205.

Frank, M. C., D. Everett, E. Fedorenko \& E. Gibson. 2008. Number as a cognitive technology: Evidence from Pirahã language and cognition. Cognition 108. 819-824.

Fuson, K. C. 1988. Children's counting and concepts of number. New York: Springer Verlag.

Gallistel, C. R. \& R. Gelman. 1992. Preverbal and verbal counting and computation. Cognition 44. 43-74.

Gentner, D. 1981c. Some interesting differences between verbs and nouns. Cognition and Brain Theory 4. 161-178.

Gentner, D. 1982. Why nouns are learned before verbs: Linguistic relativity versus natural partitioning. In S. A. Kuczaj (ed.), Language development: Volume 2. Language, thought and culture, 301-334. Hillsdale, NJ: Lawrence Erlbaum Associates.

Gentner, D. 1983. Structure-mapping: A theoretical framework for analogy. Cognitive Science 7. $155-170$.

Gentner, D. 1988. Metaphor as structure mapping: The relational shift. Child Development 59. $47-59$.

Gentner, D. 2003. Why we're so smart. In D. Gentner and S. Goldin-Meadow (eds.), Language in mind: Advances in the study of language and thought, 195-236. Cambridge, MA: MIT Press.

Gentner, D. 2005. The development of relational category knowledge. In L. Gershkoff-Stowe \& D. H. Rakison (eds.), Building object categories in developmental time, 245-275. Hillsdale, NJ: Lawrence Erlbaum Associates.

Gentner, D. 2006. Why verbs are hard to learn. In K. Hirsh-Pasek \& R. Golinkoff (eds.), Action meets word: How children learn verbs, 544-564. Oxford University Press. 
Gentner, D., F. Anggoro \& R. Klibanoff. In press. Structure-mapping and relational language support children's learning of relational categories. Child Development.

Gentner, D. \& L. Boroditsky. 2001. Individuation, relativity and early word learning. In M. Bowerman \& S. Levinson (eds.), Language acquisition and conceptual development, 215-256. Cambridge, UK: Cambridge University Press.

Gentner, D. \& M. Bowerman. 2009. Why some spatial semantic categories are harder to learn than others: The Typological Prevalence hypothesis. In J. Guo, E. Lieven, S. Ervin-Tripp, N. Budwig, S. Özçaliskan \& K. Nakamura (eds.). Crosslinguistic approaches to the psychology of language: Research in the tradition of Dan Isaac Slobin, 465-480. New York: Lawrence Erlbaum Associates.

Gentner, D. \& S. Christie. 2008. Relational language supports relational cognition in humans and apes. Behavioral and Brain Sciences 31. 136-137.

Gentner, D. \& I. M. France. 1988. The verb mutability effect: Studies of the combinatorial semantics of nouns and verbs. In S. L. Small, G. W. Cottrell \& M. K. Tanenhaus (eds.), Lexical ambiguity resolution: Perspectives from psycholinguistics, neuropsychology, and artificial intelligence, 343-382. San Mateo, CA: Kaufmann.

Gentner, D. \& S. Goldin-Meadow. 2003. Whither Whorf. In D. Gentner and S. Goldin-Meadow (eds.), Language in mind: Advances in the study of language and thought, 3-14. Cambridge, MA: MIT Press.

Gentner, D. \& J. Loewenstein. 2002. Relational language and relational thought. In J. Byrnes \& E. Amsel (eds.), Language, literacy, and cognitive development, 87-120. Mahwah, NJ: Lawrence Erlbaum Associates.

Gentner, D., J. Loewenstein \& B. Hung. 2007. Comparison facilitates children's learning of names for parts. Journal of Cognition and Development 8. 285-307.

Gentner, D. \& A. B. Markman. 1994. Structural alignment in comparison: No difference without similarity. Psychological Science 5(3). 152-158.

Gentner, D. \& J. Medina. 1998. Similarity and the development of rules. Cognition 65. 263297.

Gentner, D. \& L. Namy. 1999. Comparison in the development of categories. Cognitive Development 14. 487-513.

Gentner, D. \& L. Namy. 2004. The role of comparison in children's early word learning. In D. G. Hall \& S. R. Waxman (eds.), Weaving a lexicon, 533-568. Cambridge, MA: MIT Press.

Gentner, D., A. Ozyürek, S. Goldin-Meadow \& O. Gurcanli. 2008. Spatial language potentiates spatial cognition: Evidence from deaf homesigners. American Association for the Advancement of Science annual meeting.

Gentner, D. \& M. J. Rattermann. 1991. Language and the career of similarity. In S. A. Gelman \& J. P. Byrnes (eds.), Perspectives on thought and language: Interrelations in development, 225 277. London: Cambridge University Press.

Gentner, D., M. J. Rattermann \& K. D. Forbus. 1993. The roles of similarity in transfer: Separating retrievability from inferential soundness. Cognitive Psychology 25. 524-575.

Gentner, D. \& C. Toupin. 1986. Systematicity and surface similarity in the development of analogy. Cognitive Science 10. 277-300.

Gick, M. L. \& K. J. Holyoak. 1980. Analogical problem solving. Cognitive Psychology 12. 306-355.

Gick, M. L. \& K. J. Holyoak. 1983. Schema induction and analogical transfer. Cognitive Psychology 15. 1-38.

Goldin-Meadow, S. 2003a. The resilience of language: What gesture creation in deaf children can tell us about how all children learn language. New York: Psychology Press.

Golinkoff, R. M. \& K. Hirsh-Pasek. 2008. How toddlers begin to learn verbs. Trends in Cognitive Sciences 12(10). 397-403. 


\section{2}

\section{Gentner and S. Christie}

Gordon, P. 2004. Numerical cognition without words: Evidence from Amazonia. Science 306. $406-499$.

Gumperz, J. J. \& S. C. Levinson. 1996. Rethinking linguistic relativity. Cambridge, UK: Cambridge University Press.

Halford, G. S. 1992. Analogical reasoning and conceptual complexity in cognitive development. Human Development 35(4). 193-218.

Haryu, E., M. Imai \& H. Okada. In press. Object similarity bootstraps young children to actionbased verb extensions. Child Development.

Haun, D. B. M. \& J. Call. 2009. Great apes' capacities to recognize relational similarity. Cognition 110. 147-159.

Hirsh-Pasek, K. \& R. Golinkoff. 2006. Action meets words: How children learn verbs. Oxford University Press.

Hunt, E. \& F. Agnoli. 1991. The Whorfian hypothesis: A cognitive psychology perspective. Psychological Review 98(3). 377-389.

Karmiloff-Smith, A. 1992. Beyond modularity: A developmental perspective on cognitive science. London: A Bradford Book. MIT Press.

Kotovsky, L. \& D. Gentner. 1996. Comparison and categorization in the development of relational similarity. Child Development 67. 2797-2822.

Levinson, S. C. 2003. Space in language and cognition: Explorations in cognitive diversity. Cambridge: Cambridge University Press.

Liu, J., R. M. Golinkoff \& K. Sak. 2001. One cow does not an animal make!: Children can extend novel words at the superordinate level. Child Development 72. 1674-1694.

Loewenstein, J. \& D. Gentner. 2001. Spatial mapping in preschoolers: Close comparisons facilitate far mappings. Journal of Cognition and Development 2(2). 189-219.

Loewenstein, J. \& D. Gentner. 2005. Relational language and the development of relational mapping. Cognitive Psychology 50. 315-353.

Lupyan, G. D., H. Rakison \& J. L. McClelland. 2007. Language is not just for talking: Redundant labels facilitate learning of novel categories. Psychological Science 18. 1077-1083.

Markman, A. B. \& D. Gentner. 1993a. Splitting the differences: A structural alignment view of similarity. Journal of Memory and Language 32. 517-535.

Markman, A. B. \& D. Gentner. 1993b. Structural alignment during similarity comparisons. Cognitive Psychology 25. 431-467.

Meck, W. H. \& R. M. Church. 1983. A mode control model of counting and timing processes. Journal of Experimental Psychology: Animal Behavior Processes 9. 320-324.

Mix, K. S. 2002. The construction of number concepts. Cognitive Development 17. 1345-1363.

Mix, K. S., C. M. Sandhofer \& A. J. Baroody. 2005. Number words and number concepts: The interplay of verbal and nonverbal quantification in early childhood. In R. V. Kail (ed.), Advances in child development and behavior, Volume 33, 305-346. New York: Academic Press.

Namy, L. L. \& D. Gentner. 2002. Making a silk purse out of two sows' ears: Young children's use of comparison in category learning. Journal of Experimental Psychology: General 131. 5-15.

Novick, L. R. 1988. Analogical transfer, problem similarity, and expertise. Journal of Experimental Psychology: Learning, Memory, and Cognition 14. 510-520.

Oden, D. L., R. K. R. Thompson \& D. Premack. 2001. Can an ape reason analogically? Comprehension and production of analogical problems by Sarah, a chimpanzee (Pan troglodytes). In D. Gentner, K. J. Holyoak \& B. Kokinov (eds.), The analogical mind: Perspectives from Cognitive Science, 471-498. Cambridge, MA: MIT Press.

Penn, D. C., K. J. Holyoak \& D. J. Povinelli. 2008. Darwin's mistake: Explaining the discontinuity between human and non-human minds. Brain and Behavioral Sciences 31. 109-178.

Pica, P., C. Lemer, V. Izard \& S. Dehaene. 2004. Exact and approximate arithmetic in an amazonian indigene group. Science 306. 499-503. 


\section{AUTHOR'S COPY | AUTORENEXEMPLAR}

Mutual bootstrapping between language and analogical processing

Premack, D. 1983. The codes of man and beasts. Behavioral and Brain Sciences 6. 125-167.

Pruden, S., K. Hirsh-Pasek, W. L. Shallcross \& R. M. Golinkoff. 2008. Foundations of verb learning: Comparison helps infants abstract event components. In H. Chan, H. Jacob, \& E. Kapia (eds.), Proceedings of the 32st Annual Boston University Conference on Language Development, 2, 402-414. Somerville, MA: Cascadilla Press.

Richland, L. E., R. G. Morrison \& K. J. Holyoak. 2006. Children's development of analogical reasoning: Insights from scene analogy problems. Journal of Experimental Child Psychology 94. 249-271.

Rips, L. J., A. Bloomfield \& J. Asmuth. 2008. From numerical concepts to concepts of number. Behavioral and Brain Sciences 31. 623-642.

Ross, B. H. 1987. This is like that: The use of earlier problems and the separation of similarity effects. Journal of Experimental Psychology: Learning, Memory, and Cognition 13(4). 629639.

Simms, N. \& D. Gentner. 2008. Spatial language and landmark use: Can 3-, 4-, and 5-year-olds find the middle? In B. C. Love, K. McRae \& V. M. Sloutsky (eds.), Proceedings of the 30th annual conference of the Cognitive Science Society, 191-196. Austin, TX: Cognitive Science Society.

Slobin, D. I. 1991. Learning to think for speaking: Native language, cognition, and rhetorical style. Pragmatics 1. 7-26.

Smith, L. B., S. S. Jones \& B. Landau. 1992. Count nouns, adjectives, and perceptual properties in children's novel word interpretations. Developmental Psychology 28. 273-286.

Spelke, E. S. 2000. Core knowledge. American Psychologist 55(11). 1233-1243.

Spelke, E. S. \& S. Tsivkin. 2001. Initial knowledge and conceptual change: Space and number. In M. Bowerman \& S. C. Levinson (eds.), Language acquisition and conceptual development, 70-100. Cambridge, UK: Cambridge University Press.

Thompson, C. A. \& J. E. Opfer. In press. How 15 hundred is like 15 cherries: Effect of progressive alignment on representational changes in numerical cognition. Child Development.

Waxman, S. R. \& R. S. Klibanoff. 2000. The role of comparison in the extension of novel adjectives. Developmental Psychology 36. 571-581.

Waxman, S. R. \& D. B. Markow. 1995. Words as invitations to form categories: Evidence from 12- to 13-month-old infants. Cognitive Psychology 29. 257-302.

Whorf, B. L. 1956. Language, thought and reality: Selected writings. Cambridge, MA: Technology Press of Massachusetts Institute of Technology.

Wolff, P. \& K. Holmes. In press. Linguistic Relativity. To appear in WIREs Cognitive Science. Wynn, K. 1990. Children's understanding of counting. Cognition 36. 155-193.

Vygotsky, L. S. 1962. Thought and language. Cambridge, MA: MIT Press. Original work published 1934.

$\mathrm{Xu}, \mathrm{F} .2007$. Concept formation and language development: Count nouns and object kinds. In G. Gaskell (ed.), Oxford handbook of psycholinguistics, 627-634. Oxford University Press.

Yan, J., K. Forbus \& D. Gentner. 2003. A theory of re-representation in analogical matching. In R. Alterman \& D. Kirsh (eds.), Proceedings of the 25th annual meeting of the Cognitive Science Society. 1265-1270. 